\title{
Miscarriage-Evidence Based Information for the Web and Its Development Procedure
}

\author{
Annsofie Adolfsson 1,2*, Emelie Arbhede ${ }^{3}$, Elisabeth Marklund4, \\ Per-Göran Larsson' ${ }^{5}$, Marie Berg6,7 \\ ${ }^{1}$ School of Health and Medical Sciences, Örebro University, Örebro, Sweden \\ ${ }^{2}$ The Centre for Women's, Family and Child Health, Faculty of Health Sciences, Buskerud \& Vestfold University \\ College, Kongsberg, Norway \\ ${ }^{3}$ Department Obstetrics and Gynecology, Ryhov County Hospital, Jönköping, Sweden \\ ${ }^{4}$ Women's Clinic, Highland Distric County Hospital, Eksjö, Sweden \\ ${ }^{5}$ Department of Obstetrics and Gynaecology, University of Linköping, Linköping, Sweden \\ ${ }^{6}$ Institutes of Health and Care Science, Sahlgrenska Academy, Gothenburg University, Gothenburg, Sweden \\ ${ }^{7}$ Centre for Person-Centred Care (GPCC), University of Gothenburg, Gothenburg, Sweden \\ Email: ${ }^{*}$ annsofie.adolfsson@oru.se, emelie arbhede@hotmail.com, pg.larsson@vgregion.se, \\ marie.berg@fhs.gu.se
}

Received 27 August 2015; accepted 10 October 2015; published 13 October 2015

Copyright (C) 2015 by authors and Scientific Research Publishing Inc.

This work is licensed under the Creative Commons Attribution International License (CC BY).

http://creativecommons.org/licenses/by/4.0/

\section{(c) (i) Open Access}

\section{Abstract}

Objective: The aim of this paper is to describe the process of developing web information on miscarriage based on scientific evidence, for women and couples in Sweden experiencing miscarriage. Method: A participatory design was used which included researchers, professional experts and users. A participatory design was used involving researchers, professional experts and users. The information was developed in six stages: 1) identifying the needs of information; 2) identifying and constructing the main areas of information and its paths; 3 ) identifying and inviting experts for revision; 4) developing the text; 5) reviewing the text; 6) design and structuring for adaption to website. Results: The text of information developed gradually based on the seven steps. The final text comprised three parts: 1) what is miscarriage; 2) experiences of miscarriage; 3) processing and planning for new pregnancy. Conclusion: Using participatory design was time and resource consuming, however it was functional for producing appropriate information for the target group. The developed evidence based facts text is assumed to be a complement to the information that is provided by the health care system.

\section{Keywords}

Miscarriage, Evidence-Based Information, Women, Partner

\footnotetext{
${ }^{*}$ Corresponding author.
}

How to cite this paper: Adolfsson, A., Arbhede, E., Marklund, E., Larsson, P.-G. and Berg, M. (2015) Miscarriage-Evidence Based Information for the Web and Its Development Procedure. Advances in Sexual Medicine, 5, 89-110. 


\section{Introduction}

Becoming a mother is a process that starts early in a girl's/woman's life and which becomes more concrete when there is a decision to plan for a baby [1]-[4]. When a positive pregnancy test is a fact it is mostly a concrete start for a couples' emotional preparation and planning for an extended family with child. The maternal bond of the pregnant woman is developing and includes dreams and preparation in mind for the pregnancy, labour, birth and the prospective motherhood [1] [2].

However miscarriage, defined as a spontaneously terminated before the gestational week twenty-two [5] and of which some occur so early that the woman never realized that she was pregnant, is a fact in as many as one of five pregnancies [6]-[9].

When the pregnant woman/the prospective parents realize that the pregnancy is no longer viable they have an emotional reaction if different severity, as blockage and emptiness [2], anxiety, depression and grief [10]-[13]. For some the grieving can be on the same level as experiencing perinatal and neonatal death, or loss of a family member [11]. Some women having experienced miscarriage can also blame themselves for causing the miscarriage [2].

Lack of social support and compassionate care have been associated with prolonged emotional distress [11] [14]-[18] (Reed, 1990; Van \& Meleis, 2003). When a miscarriage has been diagnosed it is thus important that there is someone there to confirm the grief regarding the pregnancy loss, and to provide other necessary support [1] [19]-[21]. Health care professionals are in a position to keep affected couples informed about what they will be experiencing and also about various examinations and treatments [1] [22]-[24] (Brier 2011). Competent support is shown to better enable the couple to process their grief and to proceed forwards with their life [1] [4]. Research shows that women with suspected miscarriage benefit from structured information and standardized management [13].

Couples that have experienced a miscarriage would like to have support such as both oral and written information; however they are not always satisfied with the received oral information provided by the health care system with regard to the subject of miscarriage. Some never get written information, therefore the search online information [1] [2] [19] [25]. In addition, due to the emotional state it is often difficult to grasp and assimilate oral information, including such provided by health care professionals [1] [2] [4] [26]. After a period of time the couples often have new questions and concerns [1] [26]. Internet information about miscarriage may be difficult for the couple to understand and the finding are sometimes contradictive; therefore it is important that they have access to evidence-based text in popular science language as a support they can use after their initial emotional reaction to the miscarriage has subsided.

It is, to process the situation, very helpful to have access to written information [27]. In today's internet driven society people seek information via the net where they are directed to various forums and blogs where pregnancy termination is discussed by individuals of their own experiences [1]. Research shows that almost all women seek information through internet to identify web sites that provide information surrounding pregnancy and related issues. After a visit to a health care facility they mostly seek additional information from the internet. The reason that they typically were seeking further information was that they feel that they have not received adequate information from the healthcare system due possibly to time constraints in the system [28].

By constructing a factual text about miscarriage based on scientific evidence and assessed by experts in the field, and that is accessible on internet, will offer affected women and couples with correct and easily obtained information as a supplement to direct contact with the healthcare system. The aim of this paper is to describe the process of developing evidence-based factual text about miscarriage for afflicted women and couples to be used in a web page application.

\section{Method}

The project was part of a research program; MODIAB-Web, developing a web based support for women with type 1 diabetes in pregnancy and early motherhood, and tested in a randomized controlled trial. The web support included several parts of which one was to offer evidence based information to the target group. The project was approved by the Regional Ethics Board 659-09 and is registered at ClinicalTrials.gov; id-code NCT01565824. More details on the project and the RCT is described elsewhere [29] [30].

\section{Settings Participants and Procedure}

A participatory design [31] [32] where researchers, professionals and representatives of the target group all col- 
laborated was used in order to develop information based on both scientific evidence, professional experience based knowledge and on need from the target group.

Participatory design allows the project information can be seen as a democratic way to developed a project [31]. The discussion of values and the exploration of conditions are important steps in the development process among different stakeholders. In regard to developing information, participatory allows the project group to benefit from knowledge of participants on developing materials to empower a user. Participatory design can also help in developing a project that focuses on what the user needs rather than on what the healthcare provider thinks the user needs [32].

Different levels of participation may be used in designing a web-based health information site. These levels can range from deeply involved stakeholders who participate in every step of the design and development process to a more consultative role in which the stakeholders are asked to provide input during the design process [32]. In this project user involvement is closer to the latter description. The basic information about the researchers and professional experts $(n=16)$ who took part in this study, see Table 1 .

The project team responsible for the development of the information consisted of five persons. The first author (AA), a nurse-midwife with research area experiences of early miscarriage care. Supervise the two Midwife students (EA, EM) who were responsible for developing the first drafts of the text. This author developed and wrote the text with the first author. The fourth author (PGL), associated professor and gynecologist at OBGYN clinic and fourth author (PGL) Obstetrician and medicine doctor working with the target group daily read the fact text to be inconsistent with advice given. The last author (MB), a nurse-midwife and researcher specializing in diabetes care with many years' experience in developing care and constructing patient information. MB interacted in the text development on a detailed level. Different ways in each area, which had to be taken into account when developing the information. The professional experts included clinical nurse-midwives, physicians. Language reviewers and editors were also included. The information developed gradually and was thoroughly evaluated in six stages. The development of the information itself occurred during the first five stages and the adjustment to the website in the last stage.

The information was developed based on a modified method described by Linden et al. [33], including six steps, given in Figure 1.
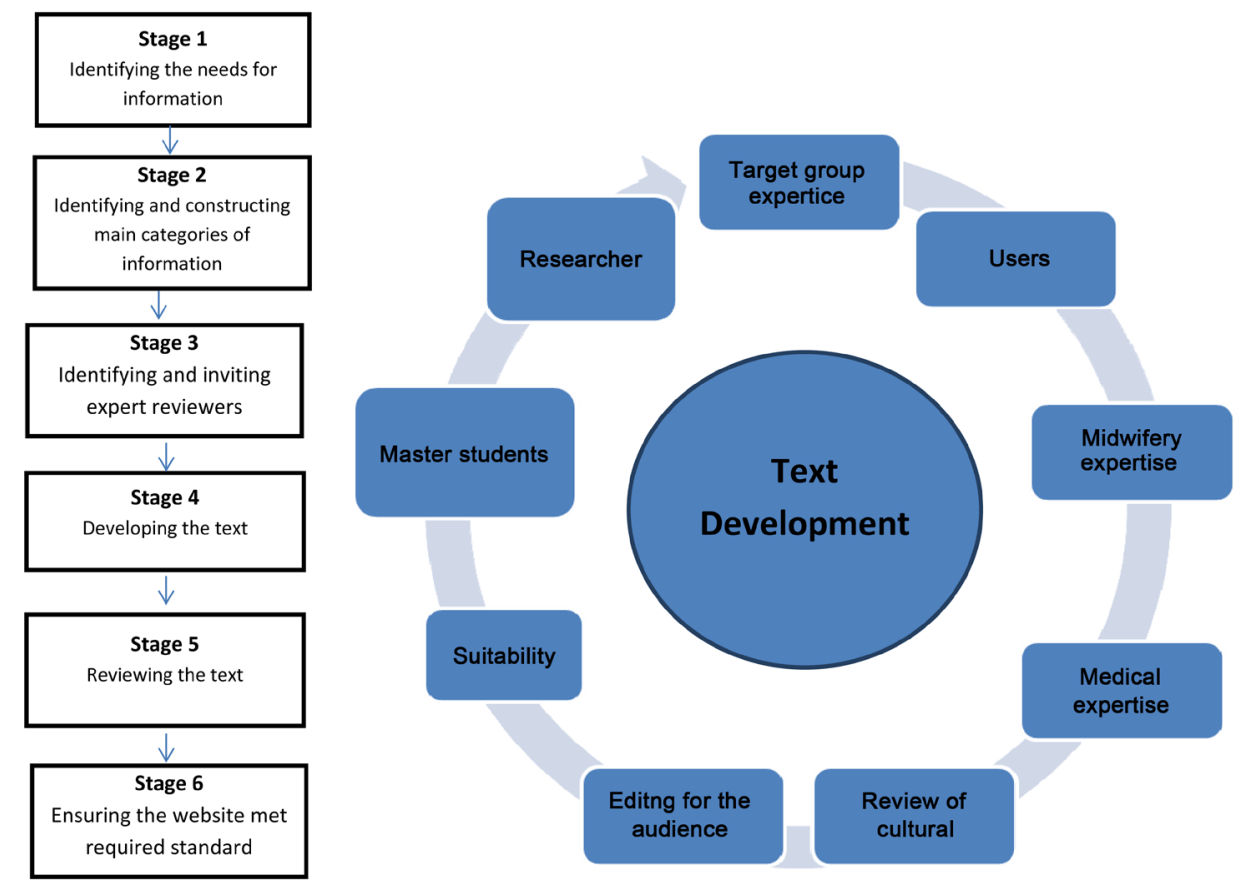

Figure 1. Six stages: 1) Identifying the needs of information; 2) identifying and constructing the main areas of information and it's pats; 3) identifying and inviting experts for revision; 4) developing the text; 5) reviewing the text; 6) design and structuring for adaption to website; the information was developed based on a modified method described by Linden $e$ al. (Linden et al. 2013), including six steps. 
Table 1. Categories, sub-categories and content of factual text in Appendix.

\begin{tabular}{|c|c|c|}
\hline Category & Sub-category & Content \\
\hline \multirow[t]{5}{*}{ What is miscarriage } & Symptoms & \\
\hline & Classification of miscarriage & $\begin{array}{l}\text { Complete, incomplete, delayed, } \\
\text { threatening and repeated miscarriages }\end{array}$ \\
\hline & Treatment for miscarriage & $\begin{array}{l}\text { Complete, incomplete and delayed miscarriage, } \\
\text { prophylaxis of miscarriage of Rh-negative woman }\end{array}$ \\
\hline & Causes of miscarriage & \\
\hline & Differential diagnoses & Molar pregnancy, ectopic pregnancy \\
\hline Experience of miscarriage & $\begin{array}{l}\text { Grief in miscarriage } \\
\text { The woman's experiences in miscarriages } \\
\text { The partner's experiences at the miscarriage }\end{array}$ & \\
\hline $\begin{array}{l}\text { Processing and planning } \\
\text { for new pregnancy }\end{array}$ & The period after miscarriage new pregnancy & \\
\hline
\end{tabular}

\section{Stage 1: Identifying the needs of information}

As a first step, existing materials were identified and analyzed; this included scientific papers, the current patient information used at the hospitals, the national guidelines regarding early miscarriage public and the material concerning miscarriage published by the Swedish Society of Obstetrics and Gynecology.

Stage 2: Identifying and constructing the main areas of information and its pats

The need of information was then determined and categorized into three main areas with separate parts. A first draft was written.

Stage 3: Identifying and inviting experts for revision

The project team identified the experts needed to review the information and contacted them primarily by email asking for their contribution.

Stage 4: Developing

A final draft was written. It was also reviewed in terms of its Linden et al. BMC Medical Informatics and Decision Making 2012, 12:134 Page 2 of 9 http://www.biomedcentral.com/1472-6947/12/134 cultural appropriateness and unnecessary jargon was removed.

Stage 5: Reviewing the text

The final draft was reviewed by midwifery and Obstetrician/Gynecologist and target group expertise.

Stage 6: Design and structuring of website

The authors oversaw the design and development of the web-site. Fitting images were chosen to illustrate themes in the text and enhance lay-out and design of the website.

\section{Results}

An overview of the six stages is given in Figure 1 and here follows details in each stage.

\section{Stage 1: Identifying the needs of information}

The first stage identified the information needs of the target group. The research team read and analyzed scientific literature of Miscarriage. The team also examined and studied local care guidelines and national policies. The information constructed by the Swedish Society of Obstetrics and Gynecology [34] was also examined and used as a source of inspiration. From this analysis, the team identified the needs for information. The couples who had experienced and suffered a miscarriage felt that there was in equate information, about physical reaction such as pain, bleeding. Lack of written information [19] [20] [23] [24] [27]. After an event such as a miscarriage couples are too overwhelmed with their grief to fully and comprehensively comprehend the information provided to them orally [2].

Stage 2: Identifying and constructing the main areas of information and it's pats

In stage 2, the research team used the information needs identified in stage 1 to construct the main categories of information. Three main categories were identified: what is miscarriage, experiences of miscarriage, processing and planning for new pregnancy, see Table 1.

The need of information was then determined and categorized into three main areas with separate parts. In- 
clusion criteria were scientific papers that met the aim of the study. Exclusion criteria were review articles. These included articles that corresponded to the studies aim and were read through several times. Articles were even searched manually and individually from the articles reference lists.

The literature search was conducted regarding spontaneous abortion and the experiences of the women together with their partners' needs of information related to the event. Scientific articles were searched during the months of October and November 2012 from databases Medline and Cinahl. A dropbox was used so that the studies two authors (EA; EM) would have access to the articles. Articles were save in different folders in order to categorize what the articles were about which made the bulk of material easier to manage and access.

Key words were used to address the purpose of the study. The words used were; miscarriage, spontaneous abortion, experience, treatment, symptoms, somatically symptoms, threatened abortion, missed abortion, incomplete abortion, risk factors and support. MeSH and the Karolinska Institute website was used in order to obtain an accurate translation of medical terms. Key words were combined with each other to reduce the number of response hits in the database to address the aim of the study. One or more keywords were combined with each other using truncation or by putting "and" or "or" between keywords in the databases Medline and Cinahl [35]. Searches conducted with the various combinations of words generated hundreds of articles. After a review of the titles and the abstracts of the articles twenty-four scientific articles included into evidence based information about miscarriage for the couple experiencing a miscarriage.

The boundaries for the Cinahl search were the words "peer-reviewed" and "English". For the Medline search the boundaries used were "journal article" and "English". In order to access the more recent articles the time limitation was limited to the years 2002-2012. Despite the time limitation the authors broadened the search for older articles before the year 2002. There was even a fictional book that was included in the results as it was difficult to classify the information to miscarriage, molar pregnancy and ectopic pregnancy in scientific articles.

The project group ensured the website met Health on the Net Foundation's code of conduct as well as St vilia et al.'s Model for Online Consumer Health Information Quality. The scientific articles included in the study corresponded to the aim of the study. The included articles would be approved by an ethics committee and the authors of the original articles should have adhered to the four basic ethical principles in their research. The four basic ethical principles are autonomy, integrity, harmless and doing good Ethical guidelines for nursing research in the Nordic region [36]. The participants that made up the expert group that reviewed the text remain confidential. By reviewing the articles several times the integrity of the study was not compromised [23].

\subsection{What Is Miscarriage}

Approximately twenty percent of pregnant women will experience bleeding at some time during their pregnancy and around half of these pregnancies are terminated with a miscarriage before twenty-two weeks into the pregnancy [37] [38]. A percentage of pregnancies terminate before the woman even knows that she was pregnant. Miscarriages are classified based upon how much time has elapsed since the pregnancy was initiated along with how the miscarriage begins and what is left for residual matter in the uterus based upon the ultrasound examination. Miscarriage is divided into early and late miscarriage. Early miscarriage occurs before the gestational week thirteen and late miscarriage is designated beyond the thirteen week mark [37] [39].

\section{Symptoms of Miscarriage}

Vaginal bleeding is a common symptom that pregnant women can experience during the first trimester of their pregnancy [40] [41]. Bleeding may occur in approximately two out of ten pregnant women sometime during their first trimester and around half of these women experiencing early bleeding will end up experiencing a miscarriage [41]. Women bleeding during a miscarriage find that the amount of bleeding varies [41] [42]. The connection between bleeding and miscarriage is well known and documented in early pregnancy. Bleeding generates alarm and anxiety in pregnant women even if a live fetus is evidenced with vaginal ultrasound examination [42]. The Hasan et al. [40] study examines the relationship between vaginal bleeding during the first twenty weeks of pregnancy and abortion rates. It was found that women who bleed more heavily (compared to the normal menstrual bleeding) has a three time higher risk of experiencing a miscarriage compared to women that are not bleeding during their pregnancy. There is a relationship between women that are experiencing heavy bleeding accompanied with pain. Women that have persistent spotting or bright red bleeding with pain for several days are at risk for having a miscarriage. There is no increased risk for a woman that is experiencing light va- 
ginal bleeding without pain that lasts for one or two days in duration during pregnancy. Maternal age, previous miscarriage and smoking was found to have no affect on the outcome if the bleeding leads to a miscarriage (ibid).

\subsection{Classification of Miscarriage}

\subsubsection{Full Miscarriage}

Full miscarriage (abortus completus) defines that the entire pregnancy has spontaneously been aborted. All fetal, placental and membranes have been expelled at the same time. The associated bleeding gradually decreases and disappears. The uterus contracts when the pregnancy is terminated with fetal matter evacuated and is reduced in size. A vaginal ultrasound evidences an empty uterine cavity and closed cervix [37] [39].

\subsubsection{Incomplete Miscarriage}

Incomplete miscarriage (abortus incompletus) usually occurs after the tenth week of pregnancy and the fetal matter and placental membrane is expelled in stages or parts over the course of a few days. The reason that the miscarriage is carried out in two stages is because the anchoring villi has developed between the eighth and twelfth week of the pregnancy and the definitive placenta has been established. The fetus is expelled first, then the amnio membrane tissue is left to be expelled in a later sequence [37]. The symptoms of an incomplete miscarriage is lower abdominal pain accompanied with heavy vaginal bleeding [37] [39]. The diagnosis is made by an ultrasound examination. With the ultrasound, the mouth of the uterus is seen as opened with pregnancy tissue residue present in the opening. The endometrial layer is more than $15 \mathrm{~mm}$ and a fetus without cardiac activity is present. The residual tissues should be removed to reduce the pain and bleeding and to prevent the risk also of cervical vasovagal shock [39]. The bleeding will continue until the entire pregnancy is aborted [37].

\subsubsection{Delayed Miscarriage}

Delayed miscarriage (missed abortion) means that the fetus has died in the womb without any bleeding occurring. The woman may experience a brief period episode of vaginal spotting or evidence a brownish discharge that rapidly dissipates. Some women may continue to experience early pregnancy symptoms while the symptoms of others disappear. Women may seek treatment when the pregnancy symptoms subside and the abdominal circumference ceases to increase. The diagnosis is normally made by the ultrasound examination. The ultrasound reveals a conjunctiva sack that is more than $20 \mathrm{~mm}$ in diameter but with no viable pregnancy present. To confirm the diagnosis a supplement ultrasound is perform with a trans vaginal ultrasound. A follow up trans vaginal ultrasound may be necessary in another week or two to confirm that there is no fetal growth. The reason that the uterus can retain a dead fetus is because the placenta continues to produce progesterone and estrogen. That some of the dead fetus tissue is retained in the uterus is because the placenta's production of progesterone is intact for a longer time or a shorter time while a decrease in estrogen occurs. The estrogen production can only be maintained as long as there is a live fetus. This changing hormone production leads to uterus muscle volatility the ability to contract is reduced which prevents the ejection of the pregnancy matter [37] [39]. The treatment of miscarriage depends upon the age of the pregnancy, bleeding and signs of infection. With a pregnancy of less than thirteen weeks an expectance may be an option [39].

\subsubsection{Threatened Miscarriage}

Threatened miscarriage (abortus immenence) occurs in around one in seven pregnancies and of these around twenty percent result in a miscarriage [39]. Symptoms of an imminent miscarriage is minor vaginal bleeding in the first trimester in combination with pain, particularly in the lower back [37] [39]. The bleeding is typically minor and disappears quickly. When the threatened abortion runs its course, the pregnancy proceeds and the woman gives birth to a child around the expected date of delivery. If the bleeding changes in severity by becoming heavier and more persistent it suggests that the miscarriage is no longer only threatening but it is completed. To determine if the miscarriage is threatening or complete a vaginal ultrasound is performed. When the diagnosis is threatened miscarriage the vaginal ultrasound reveals an intact cervix with the cervical canal closed which confirms a viable pregnancy with a uterine size consistent with the estimated gestational age. Typically the uterus appears to be enlarged and soft [37] [39]. The alternative diagnosis is a complete miscarriage, an early intrauterine pregnancy that cannot be detected by the ultrasound or an ectopic pregnancy. In order to ensure that 
the woman is experiencing only a threatening miscarriage she is administered serum levels of human chorionic gonadotropin (HCG) followed by ultrasound examination in the next 10 to 14 days [39].

\subsubsection{Repeated Miscarriages}

Repeated miscarriage is defined as three or more successive miscarriages that occur approximately at the same time in the pregnancy. After experiencing a miscarriage the risk for a subsequent miscarriage during the next pregnancy is still the same as normal, in the ten to twenty percent range. After the couple has had a third miscarriage the risk of the next pregnancy terminating in miscarriage is fifty percent if no investigation is done. The reason that the couple is experiencing repetitive miscarriages may be due to maternal, sperm or genetic issues. A thorough investigation is done after three miscarriages. Depending upon the results of the investigation there may be some treatment that may be prescribed to influence a positive outcome of the next pregnancy [37].

\subsection{Treatment of Miscarriage}

The treatment of miscarriage depends upon whether the miscarriage is a complete, incomplete or a delayed miscarriage.

\subsubsection{Full Miscarriage}

If the ultrasound examination verifies that the miscarriage is complete with an image of the empty uterus with no visible pregnancy and the endometrial lining thickness is less than $15 \mathrm{~mm}$ then no further treatment is probably necessary [43] [44].

\subsubsection{Incomplete Miscarriage}

An incomplete miscarriage is evidenced with a vaginal ultrasound that shows an endometrial lining thickness greater than $15 \mathrm{~mm}$ and there is residual pregnancy tissue remaining in the uterus [43] [45]. Incomplete miscarriage can be treated with expectance, medical or surgical treatment [45].

\subsubsection{Expectance}

An incomplete miscarriage may be treated with a few days expectance in order that the body might in a natural response expel all of the pregnancy remains. The women are informed that vaginal bleeding will continue accompanied with acute abdominal pain. The pain might be remedied with paracetamol and/or codeine. To eliminate the risk of infection the woman is advised not to bather or engage in intercourse for the proceeding two weeks. If the body is not capable of completing the miscarriage on its own the woman may need medical treatment [45].

\subsubsection{Medical Treatment}

Medical treatment means that the woman should be administered a medicine containing prostaglandin to assist the uterus to contract and expel the remains of the pregnancy [45]. Women receiving medical treatment for miscarriage should follow up with hCG in serum or urine to rule out ectopic pregnancy and chorionic malignancy according to Nielsen et al. [44]. Within fourteen days the woman is called in for an appointment to verify that the pregnancy has totally expelled itself. Should the women experience heavy bleeding, become circulatory influenced or have an infection of the pregnancy tissue she may require a haemostatic curettage [45].

\subsubsection{Surgical Treatment}

Haemostatic curettage is usually performed with general anesthesia after the cervix is dilated with the administration of prostaglandin. When the heamostatic curettage is scraped the pregnancy tissue is vacuumed out with a suction device. Women who have the haemostatic curettage generally experience several fewer days of bleeding and have less pain than those that elect for expectance or medical treatment [45] [46].

\subsubsection{Delayed Miscarriage}

In a delayed miscarriage the expired fetus remains in the uterus for some weeks because the body for some reason has not rejected and expelled the contents of the aborted pregnancy. With an ultrasound examination the viability of the fetus can be verified [43]. This is treated the same as an incomplete miscarriage [45]. 


\subsubsection{Prophylaxis of Miscarriage of Rh Negative Women}

The woman's medical journal should have documented the blood type of the woman and whether she is Rhesus (Rh) positive or negative [47]. Women who are Rh negative who experience a miscarriage or threatened miscarriage after the twelfth week of pregnancy should receive anti-D immunoglobulin for the prevention of Rh immunization [39] [47]. When a miscarriage occurs before the twelfth weeks of pregnancy where the woman has received medical or surgical treatment, has heavy bleeding or might be suspected of having an ectopic pregnancy the woman should be administered anti-D prevention [39].

\subsection{Causes of Miscarriage}

The cause of each individual miscarriage case is seldom known. The most common cause of miscarriage is chromosomal abnormalities which may be seen in fifty-four percent to seventy-six percent of miscarriages [48]. Defects to the fertilized egg [48], chronic diseases of the woman such as immunological disorders, antiphospholipid syndrome (APS) [49], or thrombotic diseases such as activated protein C resistance [50]. Women with endocrine diseases such as hypothyroidism and polycystic ovary syndrome have an increased risk of miscarriage [7] [50]. Women with insulin treated diabetes who enter pregnancy with poor therapeutic blood glucose are at a higher risk for miscarriage compared to women who have good therapeutic blood sugar. Congenital malformations of the uterus add to an increase in risk of miscarriage. The risk of miscarriage increases with the age of the woman [7].

A Cramer and Wise [49] study revealed that women who are under twenty-five years of age have a twelve percent risk of miscarriage. The risk for women over thirty-nine years of age is eighteen percent (ibid). Another study shows that there is no difference in the risk of miscarriage for women under the age of thirty-five but the risk increases by seventy-five percent for mothers aged thirty-five to thirty-nine years and there is a fivefold increase for risk in women over forty [51]. Women who have a Body Mass Index (BMI) of under 18.5 before pregnancy are at a higher risk while BMI over 25 has no effect (ibid).

Women that have an infection during the early stages of pregnancy may have an increase it their risk for miscarriage. The infection may be genital or viral infections. Infections such as mycoplasma, chlamydia and bacterial vaginosis have been shown to increase the risk of miscarriage [49] [51]. Women who have a primary genital herpes infection in the early pregnancy have an increased risk for miscarriage. Other infectious diseases, rubella (German measles), cytomegalovirus, listeria and toxoplasma gondil. Other factors in the woman's environment can also increase her risk for miscarriage such as passive smoke. Women who smoke have a higher risk of miscarriage than non-smokers and the risk increases with the number of cigarettes per day. Not surprisingly alcohol intake also increases the risk of miscarriage [7]. Women who feel happy, relaxed and in control during the first twelve weeks of pregnancy reduce their risk for miscarriage. Women who have experienced stressful and traumatic events during their pregnancy are at an increased risk for miscarriage [51].

\subsection{Less Common Diagnosis of Miscarriage}

Molar pregnancy (hydatidiform mole) and ectopic pregnancy (ectopic pregnancy) are examples of less common miscarriage diagnosis. If a woman is bleeding in the first and second trimester of her pregnancy it may be due to a molar pregnancy. During a molar pregnancy the uterus is disproportionate and serum levels of hCG (human chorionic gonadotropin) are on the high side compared to the pregnancy week. An ectopic pregnancy is characterized by one-sided, intense and sharp pain with sparse vaginal bleeding [37].

\subsubsection{Molar Pregnancy}

Molar pregnancy is a rare complication of pregnancy as it affects only one out of twelve hundred pregnancies in the western world. Molar pregnancy occurs primarily in young women under fifteen years of age or in women more than forty-five years of age [39]. There are two forms of molar pregnancy, complete and partial molar pregnancy. With a complete molar pregnancy a fetus was never formed. A partial molar pregnancy has a formed embryo that dies in the eighth or ninth week of pregnancy. Molar pregnancy is formed in the fifth to seventh weeks. With a molar pregnancy there is chorionic villi present after the implantation of the fertilized egg with an imperfect or faulty development. Chorion villi vascular degeneration formed and trophoblast develops into a blister like structure. The trophoblasts layer retains the endocrine acting secreted hCG which causes the pregnancy to grow rapidly and it fills the uterus cavity. The fetal circulation is missing and the uterine cavity is filled 
instead with blisters. The etiology behind this indicates a probable absence of maternal chromosome set by the egg that has been fertilized with a double set from the father [37].

Molar pregnancy diagnosis is made from the combination of the woman's medical history in conjunction with ultrasound and blood tests. The symptoms that a woman will normally identify are minor bleeding and pain which can mimic the symptoms of a miscarriage [37]. When no viable pregnancy can be evidenced and the doctor suspects that the uterine cavity is filled with blisters instead of fetus and placenta tissue the pregnancy is treated surgically. A haemostatic curettage is performed and the contents that are suctioned out of the uterus are sent to the pathologist for analysis. After the contents of the pregnancy are removed the serum levels of hCG are examined to assure that no molar residual is left. Pregnancy should be abstained from for up to a year until normal hCG levels are attained. This is because hCG levels rise both in a normal pregnancy and in a molar pregnancy. To rule out that there are no remaining residual from the molar pregnancy another pregnancy must avoided. Molar residuals left behind can form into chorion carcinoma which is a form of a malignant tumor [39].

\subsubsection{Ectopic Pregnancy}

An ectopic pregnancy occurs when the fertilized egg is implanted outside of the uterine cavity. This is a condition that occurs in roughly two percent of early pregnancies. In ninety-nine percent of all ectopic pregnancies the implantation of the fertilized egg occurs in the fallopian tubes but it can occur in the ovaries and in the abdominal cavity as well. Clinical indications of an ectopic pregnancy are when there is soreness when palpitating the lower abdomen or palpitation soreness beside or behind the uterus. Usually a confirmed diagnosis is obtained with a transvaginal ultrasound. Risk factors for ectopic pregnancy are inflammation of the ovaries, intrauterine devices (IUD), sterilization, former fallopian tube surgeries, previous ectopic pregnancy or infertility [37].

The symptoms of ectopic pregnancy first appear between six to eight weeks after the last menstrual period [37]. Of the woman that experience an ectopic pregnancy, ninety-five percent complain of symptoms as abdominal pain or pain on one side of the lower abdomen [52]. Unlike miscarriage heavy bleeding is never an outward symptom. In thirty percent of tubular pregnancies the pregnancy is terminated with a tubal rupture. A tubal rupture occurs four to eight weeks after the last menstrual period [37]. Without any warning the woman experiences acute intense pain to one side of the lower abdomen due to the rupture of the tube. Such a rupture can cause a woman to feint or even lose consciousness which may leave her in a state of shock as well. The intraabdominal bleeding that can occur with such a rupture may be so profuse that the woman's life may be endangered [37] [52].

The treatment of an ectopic pregnancy may be done surgically with a laparoscopy procedure or treated medically with methotrexate treatment (chemotherapy) depending upon the clinical analysis. The choice of treatment is dependent upon the hCG levels. At higher levels there runs the risk of tubal rupture. Surgical treatment is either done with a tubalatomy which is a procedure that only removes the pregnancy residuals or a salpingectomy which involves removing the affected fallopian tube. This procedure will not reduce the chance of becoming pregnant again. Methotrexate treatment is given to woman when the ectopic is diagnose early enough and it works by stopping the embryo cells from growing and afterwards the contents is reabsorbed. After the treatment of the extra uterine pregnancy the serum levels of hCG are controlled [37].

\subsection{Experiences of Miscarriage}

Experiences are presented in the subcategories of "Grief in miscarriage”, "Woman’s experiences of miscarriage” and "Partner's experiences with miscarriage.

\subsection{Grief with Miscarriage}

The woman and her partner often are chock and distraught when they receive the ultrasounds finding that the pregnancy is no longer viable. When this is confirmed by the ultrasound screen that does not show any evidence of life they can lapse into a state of shock and feel a deep sense of despair. In this type of unbalanced emotional state they are often unable to fully comprehend the information that they are being given and they end up going home full of their concerns. It is vitally important that the grieving couple's sad state is recognized and that they are treated professionally with adequate empathy and sympathy [2]. The grief produced by a miscarriage is extremely difficult and trying emotionally which can make it difficult to manage. The loss of the dream comes 
swiftly and unexpectantly without any warning signs save for the preliminary symptoms. Grief that is not processed can develop into a "debt" against the next pregnancy. Couples react differently to grief. They may experience dizziness, anxiety or the inability to sleep [6]. After a loss such as miscarriage it is normal and natural to feel substantial grief. In today's society we are socialized to believe that these feeling may be unnatural and abnormal [53].

Grief cannot be divided up into phases or stages. But those that are in mourning experience many of the same reactions. The reactions that are described below are normal and natural reactions to loss. How long the duration of the reaction is up to how each individual responds and not everyone experiences these reactions [53].

Reduced concentration... A person in mourning typically has difficulty concentrating and they are often fully occupied with the feelings that the grief has brought to them.

A sense of anesthesia... In a sense it is sort of anesthesia. The feeling can be numbing both physically and emotionally. The anesthesia lasts for different lengths of time depending on the individual.

Irregular sleep... Sleeping disruptions or irregularities may vary from day to day. They can switch between not being able to sleep to sleeping unusually deep and long.

Change in eating habits... Similarly to the sleeping disorders, eating problems may vary from not having any appetite at all to eating too much. These reactions too can vary from day to day.

Emotional roller-coaster... The emotions provoked by such a disappointing event leaves the victim feeling emotionally and physically exhausted because of the emotional swings [53].

\subsubsection{Women's Experience of Miscarriage}

Having a spontaneous abortion means the loss of an expected child to the woman regardless at what stage of her pregnancy this has occurred [2] [54] [55]. The miscarriage itself symbolizes the loss of a baby, maternity, hopes and dreams for the future that women feel ownership of from the moment of conception to the reinforcement of the positive pregnancy [2] [55]. Women describe feeling of sadness, pain anxiety, guilt and profound emptiness [2]. They also feel some fear and panic surrounding the whole experience as they try to understand what exactly has happened to them [54] [55]. Miscarriage is an unexpected and it is the last thing in the world that a mother to be would wish to happen and a unexpected shock of this magnitude leads the women to question themselves as to why it happened to them [2] [54]-[56].

Many women describe having feelings that something was wrong with their pregnancy before the miscarriage occurred. Women naturally want to find explanations for why the miscarriage happened and they can end up blaming themselves for the outcome. They can see their bodies as incapable of carrying out the pregnancy and giving birth to a child or they can blame themselves for not doing everything they could to prevent the miscarriage [2] [54] [56]. The women who have reoccurring miscarriages experience it as a personal failure so it is vitally important that the healthcare provided to them will free them from the guilt and the anxiety that is a result of the episode. It is important that they can feel that there was not anything that they did wrong [54]. The loss of the pregnancy can lead to an internal conflict in the woman and this conflict can easily lead to depression if her feelings are left unresolved. If the woman does not share the disappointment it can lead to a feeling of isolation and further anxiety. It can also lead to anxiety and suffering when it comes to a new pregnancy [55]. The loss of the pregnancy is an emotional, physical and mental strain for women when their immediate plans for the future are unexpectantly dashed. Partly as a consequence of this the women may feel that they have been provided with inadequate information about miscarriage when it occurs [54] [55]. There are women that have had bleeding during their pregnancy that called the healthcare for advice and were told that the bleeding was not dangerous and they are not to worry. This may cause them to feel rejected. Women who end up going to the emergency ward with bleeding feel left out because they may have to wait an inordinate amount of time for a doctor to tell them what they believe. Women who suffer a miscarriage experience it as a personal failure. They often end up attributing the blame for the failure on themselves.

\subsubsection{The Partner's Experience of Miscarriage}

The partner of the woman has a different experience of the miscarriage than the woman does. They might find the event to be frightening. It is difficult to stand idly by and watch the woman writhing in pain and bleeding. The partner is worried and afraid of something happening to the woman [57]. The partner may cry at first as their initial reaction when they receive the news that there has been a miscarriage and then they want to move on. It is difficult for them to understand why the woman must continue to mourn for days and even weeks while 
having the need to think and talk about what happened to them. If the partner does not feel like talking about the miscarriage when the woman does it can be a source of conflict and have a distancing effect on the relationship. The partner does not have the same needs as the woman to talk about the miscarriage [2]. This is actually quite normal and understandable as the partner does not perceive the disappointment on the level as the woman who after all had a developing fetus in her own body [57]. With the loss the partner tries to show strength and protectiveness. They put their own feelings of grief and anger aside. It may be difficult for the partner to provide emotional support when they are experiencing their own feelings of being stressed and at a loss of explanation for the event. The partner's intention is to provide emotional support which they may attempt to do by practical awareness rather than emotionally. The woman might find this type of support inadequate which in turn may lead the partner to feel guilty and unappreciated [58].

Processing and planning for new pregnancy. Things to consider after the miscarriage and facing a new pregnancy

Divided into the subcategories "The period after the miscarriage" and "New pregnancy".

\subsubsection{The Period after the Miscarriage}

The initial time after the miscarriage is understandably difficult and the tears can come out of nowhere without any sense of control. Women can have the feeling that they will never come to feel good again. Some of this can be attributed to the presence of high hormones in the body. She may find it difficult what she get the first menstruation as it will remind her that she is no longer pregnant. The first menstrual cycle usually comes later than normal. The bleeding is heavier containing blood clots and the pain is stronger than before the miscarriage. Many couples are still longing for a child after the miscarriage but it is quite common for them to wonder if they dare to try it again. It is recommended that the woman think things through thoroughly and wait to attempt to get pregnant again until she has resolved her feelings about here miscarriage. This will give the couple a fresh opportunity to make the necessary decisions as to when they will be ready for a new pregnancy. During these difficult times it is important that they do not avoid being close to one another and avoid intimacy. But it is good to wait on a new pregnancy until the menstrual cycle has returned to normal [57].

\subsubsection{New Pregnancy}

Women who have suffered a miscarriage often have mixed feelings initially about getting pregnant again. With the advent of a new pregnancy their feelings my oscillate between feeling of joy to feelings of fear and anxiety [2] [25] [59]. It is common for the woman to distance herself from a new pregnancy. She understandably wants to protect herself from the strong sense of disappointment that she experienced when she miscarried [2] [59]. Even if the woman manages to get pregnant again she may find it difficult to the real joy attached to it. To make the potential disappointment of another miscarriage more manageable the couple may avoid making the purchase of baby things, they may tell their friends and family that they are expecting another child or that they have an appointment for enrollment for women's healthcare [59]. It is not uncommon for women to focus and pay close attention to their pregnancy symptoms. Knowing that the symptoms have a calming effect on the woman. Symptoms such as nausea, fatigue and sore breasts give her that sense of security and the sense of identity of a pregnant woman. The absence of bleeding also brings her comfort [25] [59]. Many women feel more secure once they have had an early ultrasound examination to confirm that they have a live fetus in their womb. It is a matter left to the individual how long this makes the woman feel secure. They know from their previous experience with miscarriage that there are no guarantees [25]. Many of these women need extra support and advice when they enter a new pregnancy. When they get a positive pregnancy test result it may create an anxiety that makes it difficult to manage by herself. She may find that she needs professional counseling with a counselor or a health care professional where she can talk about her miscarriage experience and her concerns for the new pregnancy. Waiting for the call to enroll in the women's healthcare seems like a long time for the woman who is managing her fear and anxiety on her own [59]. There are also women that go into the new pregnancy without being worried about another miscarriage and who dare to believe that they are going to be successful [25].

\section{Stage 3: Identifying and inviting experts for revision}

In stage 3, which ran parallel to stage 2, the team identified experts in different fields and invited them to review the text. The experts were identified as the text was developed. In total, 13 people, midwife, obstetrician, gynecologist, research team and professionals and representatives from the target group, participated. They included 
two clinical nurse-midwives, three physicians specializing in obstetrics and gynecologic care. There were also two mothers and one couple. Simultaneously with the preparation of the scientific text the popular scientific fact text was created, see Appendix.

\section{Stage 4: Developing the text}

In stages 4, the text was developed as part of an intertwined process and therefore both stages are described together. After each person provided input, the project team reached a consensus on what to include and to omit. The experts' comments is described below.

The project group ensured the website met Health on the Net Foundation's code of conduct as well as St. vilia et al.'s Model for Online Consumer Health Information Quality. The scientific articles included in the study corresponded to the aim of the study. The included articles would be approved by an ethics committee and the authors of the original articles should have adhered to the four basic ethical principles in their research. The four basic ethical principles are autonomy, integrity, harmless and doing good (Ethical guidelines for nursing research in the Nordic region, 2003).

Stage 5: Reviewing the text

The participants that made up the expert group that reviewed the text remain confidential. By reviewing the articles several times the integrity of the study was not compromised [36].

\subsubsection{Review of Cultural Suitability}

After the reviews by the experts and the target group, all of the written information was assessed in regard to its cultural suitability and readability. This assessment was conducted by three skilled professionals: a journalist and director of a patient information website, a medical secretary, and a nurse-midwife with a master's degree. To evaluate the text they were provided with the criteria of the Suitability Assessment of Materials [25]. The instrument was partly used and the text was reviewed in regard to its content, literacy demand, learning stimulation and motivation as well as its cultural appropriateness. Some changes to language and context were made and some parts were removed as they were found to be unnecessarily detailed. For example, the section on instrumental birth was reworked as it was too specific.

\subsubsection{Editing for a Lay Audience}

The text was professionally edited to remove unnecessary jargon and to ensure that it could be understood by its intended readers. The research team hired a commercial company specializing in popular science editing for this purpose. They changed the order of the paragraphs and reorganized the parts in a way that further enhanced the text, making it more comprehensible. Making these changes improved the flow and readability of the text. As a last step, the first, second and third authors reviewed the text to make sure that no meanings had been changed unintentionally and that no significant information had been removed.

\section{Stage 6: Design and structuring of website}

In stage 6, the website was designed and laid out by web developers. The researchers had input on the design. An overview of the final information with categories and content is presented in Table 1 . In order to avoid overwhelming the user with information, the parts of the categories have been kept independent or separately as the user wishes. This allows the user to select only the sections of desired information. In this stage, images and links were added to enhance and complement the understanding of the text. Fitting images were chosen by the first and the third authors, who checked copyrights and acquired permissions needed. Links were also provided to evidence-based sites with general information about pregnancy, labour, breastfeeding and diabetes. The structure of the information on the website was assessed by three pregnant women having diabetes type 1 . The evidence based text is in Appendix.

\section{Discussion}

Developing information based on scientific evidence and on experience-based professional knowledge through a participatory design was functional, although time consuming. The process benefited greatly from having a heterogeneous group of experts assessing the materials independently. Having access to a group consisting of experts in medical care, popular science editing, women who had lived experience of miscarriage proved indispensable because the final text would not have been as thorough and well thought out without their input.

Reaching a consensus on what to include or omit after each expert's review and revision required time for reflection on the part of the research group. Using participatory design proved an effective way of ensuring that the 
information provided reflected what the women wanted to read about [32]. Having input from both professionals and women/mothers who had experience of miscarriage provided insights that were invaluable to the project team.

Getting the mothers' opinions was undoubtedly the most important part of the review process, a step that could not have been left out. Their comments allowed the research text to better suit their needs, as is vital in evidence based information [60] [61].

Developing specialized information is a challenge. There is often a gap between what the health professionals want the reader to know and what the reader is expecting to read. In traditional patient information for patients with miscarriage [62]. In moving towards a model of shared decision making, evidence-based information is necessary for making informed choices [24] [63].

There appears to be a lack of theory on how to measure whether patient information is comprehensible or not [64]. In this project the research team consulted a commercial company specialized in popular science editing to gain insight from professionals not biased by preunderstanding. This was helpful, but not essential. If the team had not had the insights from the target group, it probably would have missed the mark in tone and meaning. The same content may differ in perceived meaning depending on the tone of the paragraphs and headings, a valuable insight. This highlights the importance of involving members of the target group and not only skilled professionals in text development [65]. The recognition of well-known brands or symbols on a website help users of the site determine whether the information given is credible [66].

\section{Limitations}

This research project of developing information specifically designed for women and their partners with a miscarriage had some limitations. When implemented in usual care the web support needs to be translated to common foreign languages. It was important to the project group that the information reflect what the women needed.

This was done to encourage high quality and high standards of the information that was to be forwarded to a couple experiencing a miscarriage. The expert group consisted of doctors and midwives selected due to their experience and expertise in the field of miscarriage. Four doctors and four midwives were asked via an email to examine the evidence-based factual text, see Appendix.

A literature review was chosen as the method to address the aim of the study. Based on the aim keywords were combined with each other to compile information about miscarriage to the couple.

The advantage of using databases is that the articles for the study could be contained within parameters and the information would be credible. Inclusion and exclusion criteria were formulated before the searches were initiated. Inclusion criteria were scientific papers that met the aim of the study. Exclusion criteria were review articles. It was discovered that even review articles were using review articles in their studies which eliminated many articles as excluded. The authors chose to include scientific articles with both qualitative and quantitative approaches since the approach of the study was to compile information about miscarriage for experiencing couples.

The included articles were primarily from Sweden, England, Australia and America in order to increase the likelihood that the information was transferable since these countries have similar views about the subject of miscarriage.

From the analysis of the collected articles categories and subcategories were developed and presented in Table 1. The couples were thus able to choose what information they wanted to access and study. Under the miscarriage category there was a presentation of two differential analyses of pregnancy, ectopic pregnancy and molar pregnancy (Brody, 1993; Tamizian \& Arulkumaran 2004). These less common diagnosis' of miscarriage were included to point out that even though the woman gets a positive response from her pregnancy test the chance remains that all may not be as it appears to be. These types of diagnosis' can leave the woman feeling the same despair as the more conventional diagnosis' of miscarriage and she needs the same type of support and information. By getting the couple to share some basic and fundamental information together they can see that their reactions are not abnormal or different from what others feel (Adolfsson et al., 2004). The information might just be as valuable in the sense as it helps both members of the couple to get insights into how others react in their respective roles.

When the couple gets the information about the miscarriage it has the effect of crushing their hopes and dreams for the future. Many women will immediately question themselves about the things that they may have done wrong to bring on this incident (Adolfsson et al., 2004; Ancker et al., 2012; Harvey et al., 2001). Midwives need to understand how the miscarriage affects the couples individually. The health care professional need not have had to experience a miscarriage first hand in order to understand how the couple feels. 


\section{Conclusion}

Miscarriage is a fairly common event in pregnancy and is found to occur in nearly one of every five pregnancies. Miscarriage in the past has been treated as a taboo subject but in today's society it is treated more openly and discussed at length on various internet forums and blogs. There is information available about miscarriage in the healthcare guide and on 1177.se but it is possible that all couples seeking this information do not come to access it. When a couple suffers a loss of the magnitude of miscarriage they may not be emotionally present enough when it happens to them to process all of the information that is being presented. Swanson emphasizes in her research how important it is to have redundant information available to them. Yet many women relate that they feel that the information that they receive is inadequate to their needs. Evidence-based text about miscarriage and how it effects women and couples can now reach those that are effected and this can be a constructive complement to the information provided by the healthcare system.

\section{Continued Research}

Randomized control study as evaluation of application of this evidence based web based fact information.

\section{References}

[1] Wojnar, D.M., Swanson, K.M. and Adolfsson, A. (2011) Confronting the Inevitable: A Conceptual Model of Miscarriage for Use in Clinical Practice and Research. Death Studies, 35, 536-558. http://dx.doi.org/10.1080/07481187.2010.536886

[2] Adolfsson, A., Larsson, P.-G., Wijma, B. and Bertero, C. (2004) Guilt and Emptiness: Women’s Experiences of Miscarriage. Health Care for Women International, 25, 543-560. http://dx.doi.org/10.1080/07399330490444821

[3] Nelson, A.M. (2003) Transition to Motherhood. JOGNN Gynecologic and Neonatal Nursing, 32, 465-477. http://dx.doi.org/10.1177/0884217503255199

[4] Brier, N. (2008) Grief Following Miscarriage: A Comprehensive Review of the Literature. Journal of Women's Health, 17, 451-464.

[5] WHO (1977) WHO: Recommended Definitions, Terminology and Format for Statistical Tables Related to the Perinatal Period and Use of a New Certificate for Cause of Perinatal Deaths. Modifications Recommended by FIGO as Amended October 14, 1976. Acta Obstetricia et Gynecologica Scandinavica, 56, 247-253.

[6] Adolfsson, A. and Larsson, P.G. (2006) Cumulative Incidence of Previous Spontaneous Abortion in Sweden in 19832003: A Register Study. Acta Obstetricia et Gynecologica Scandinavica, 85, 741-747. http://dx.doi.org/10.1080/00016340600627022

[7] Cramer, D.W. and Wise, L.A. (2000) The Epidemiology of Recurrent Pregnancy Loss. Seminars in Reproductive Medicine, 18, 331-339. http://dx.doi.org/10.1055/s-2000-13722

[8] Hemminki, E. and Forssas, E. (1999) Epidemiology of Miscarriage and Its Relation to Other Reproductive Events in Finland. American Journal of Obstetrics \& Gynecology, 181, 396-401. http://dx.doi.org/10.1016/S0002-9378(99)70568-5

[9] Andersen, A., Wohlfahrt, J., Christens, P., Olsen, J. and Melbye, M. (2000) Maternal Age Fetal Loss: Population Based Register Linkage Study. British Medical Journal, 320, 1708-1712. http://dx.doi.org/10.1136/bmj.320.7251.1708

[10] Brin, D.J. (2004) The Use of Rituals in Grieving for a Miscarriage or Stillbirth. Women \& Therapy, 27, 123-132. http://dx.doi.org/10.1300/J015v27n03_09

[11] Bryant, H. (2008) Maintaining Patient Dignity and Offering Support after Miscarriage. Emergency Nurse, 15, 26-29.

[12] Adolfsson, A. and Larsson, P.-G. (2006) Translating the Short Version of Perinatal Grief Scale to Swedish. Scandinavian Journal of Caring Sciences, 20, 1-5. http://dx.doi.org/10.1111/j.1471-6712.2006.00404.X

[13] Adolfsson, A., Tullander-Tjornstrand, K. and Larsson, P.G. (2011) Decreased Need for Emergency Services after Changing Management for Suspected Miscarriage. Acta Obstetricia et Gynecologica Scandinavica, 90, 921-923. http://dx.doi.org/10.1111/j.1600-0412.2011.01144.x

[14] Blake-Barlow, J. (1998) Caring after Miscarriage. Kai Tiaki Nursing New Zealand, 4, 24-25.

[15] Cecil, R. and Leslie, J. (1993) Early Miscarriage: Preliminary Results from Study in Northern Ireland. Journal of Reproductive and Infant Psychology, 11, 89-95. http://dx.doi.org/10.1080/02646839308403199

[16] Puddifoot, J. and Johnson, M. (1999) Active Grief, Despair, and Difficulty Coping: Some Measured Characteristics of Male Response Following Their Partner's Miscarriage. Journal of Reproductive and Infant Psychology, 17, 89-93. http://dx.doi.org/10.1080/02646839908404587 
[17] Wojnar, D. (2007) Miscarriage Experiences of Lesbian Couples. Journal of Midwifery \& Women’s Health, 52, 479-485. http://dx.doi.org/10.1016/j.jmwh.2007.03.015

[18] Wojnar, D.M. (2005) Miscarriage Experiences of Lesbian Birth and Social Mothers. Ph.D. Thesis, University of Washington, Seattle.

[19] Adolfsson, A. (2011) Women's Well-Being Improves after Missed Miscarriage with More Active Support and Application of Swanson's Caring Theory. Psychology Research and Behavior Management, 4, 1-9.

[20] Jansson, C. and Adolfsson, A. (2011) Application of Swanson's Middle Range Caring Theory in Sweden after Miscarriage. International Journal Clinical Medicine, 2, 102-109. http://dx.doi.org/10.4236/ijcm.2011.22021

[21] Murphy, F.A., Lipp, A. and Powles, D.L. (2012) Follow-Up for Improving Psychological Well Being for Women after a Miscarriage. Cochrane Database of Systematic Reviews, 3, Article ID: CD008679. http://dx.doi.org/10.1002/14651858.cd008679.pub2

[22] Adolfsson, A. and Kjellström, B. (2014) EKO-modellen: En personalhandbok om förlorad graviditet. Effektum, Älvsjö.

[23] Rowlands, I.J. and Lee, C. (2010) The Silence Was Deafening': Social and Health Service Support after Miscarriage. Journal of Reproductive and Infant Psychology, 28, 274-286. http://dx.doi.org/10.1080/02646831003587346

[24] Paton, F. and Wood, R. (1999) Grief in Miscarriage Patients and Satisfaction with Care in a London Hospital. Journal of Reproductive \& Infant Psychology, 17, 301-315. http://dx.doi.org/10.1080/02646839908404596

[25] Rosebrink, M., Zekaj, M. and Adolfsson, A. (2012) Kvinnors upplevelser av tidig graviditet, efter att ha upplevt ett eller flera missfall tidigare i livet. Nordic Journal of Nursing Research, 32, 4-8. http://dx.doi.org/10.1177/010740831203200202

[26] Adolfsson, A. (2011) Meta-Analysis to Obtain a Scale of Psychological Reaction after Perinatal Loss: Focus on Miscarriage. Psychology Research and Behavior Management, 4, 29-39. http://dx.doi.org/10.2147/PRBM.S17330

[27] Chan, M.F. and Arthur, D.G. (2009) Nurses’ Attitudes towards Perinatal Bereavement Care. Journal of Advanced Nursing, 65, 2532-2541. http://dx.doi.org/10.1111/j.1365-2648.2009.05141.x

[28] Lagan, B., Sinclair, M. and Kernohan, W. (2010) Internet Use in Pregnancy Informs Women’s Decision Making: A Web-Based Survey. Birth, 37, 106-115. http://dx.doi.org/10.1111/j.1523-536X.2010.00390.x

[29] Berg, M., Adolfsson, A., Ranerup, A. and Sparud-Lundin, C. (2013) Person-Centered Web Support to Women with Type 1 Diabetes in Pregnancy and Early Motherhood-The Development Process. Diabetes Technology \& Therapeutics, 15, 20-25. http://dx.doi.org/10.1089/dia.2012.0217

[30] Adolfsson, A., Linden, K., Sparud-Lundin, C., Larsson, P.G. and Berg, M. (2014) A Web-Based Support for Pregnant Women and New Mothers with Type 1 Diabetes Mellitus in Sweden (MODIAB-Web): Study Protocol for a Randomized Controlled Trial. Trials, 15, 513. http://dx.doi.org/10.1186/1745-6215-15-513

[31] Gregory, J. (2003) Scandinavian Approaches to Participatory Design. International Journal of Engineering Education, 19, 62-74.

[32] Spinuzzi, C. (2005) The Methodology of Participatory Design. Technical Community, 52, 163-174.

[33] Lindén, K., Sparud Lundin, C., Berg, M. and Adolfsson, A. (2013) Study Protocol for Evaluating a Web-Support Program: For Pregnant Women and New Mothers with Type 1 Diabetes Mellitus. Proceedings of the 7th International DIP Symposium Diabetes, Hypertension, Metabolic Syndrome \& Pregnancy, Florence, 14-16 March 2013.

[34] Linden, K., Berg, M. and Sparud-Lundin, C. (2012) Web-Based Information for Pregnant Women and New Mothers with Type 1 Diabetes-A Descriptive of the Development Process. BMC Medical Informatics and Decision Making, 12, 134-148. http://dx.doi.org/10.1186/1472-6947-12-134

[35] Polit, D.F. and Beck, C.T. (2012) Nursing Research: Generating and Assessing Evidence for Nursing Practice. 9th Edition, Wolters Kluwer Health/Lippincott Williams \& Wilkins, Philadelphia.

[36] Erfoi, N. (2003) Etiska riktlinjer för omvårdnadsforskning i Norden. Vård i Norden Utveckling Forskning, 4, 10-12.

[37] Brody, S. and Frank, U. (1993) Obstetrik och gynekologi: klinisk praxis och teoretisk bakgrund. 9th Edition, Almqvist \& Wiksell, Stockholm.

[38] Everett, C. (1997) Incidence and Outcome of Bleeding before the 20th Week of Pregnancy: Prospective Study from General Practice. BMJ, 315, 32-34. http://dx.doi.org/10.1136/bmj.315.7099.32

[39] Tamizian, O. and Arulkumaran, S. (2004) Bleeding in Early Pregnancy. Current Obstetrics \& Gynaecology, 14, 23-33. http://dx.doi.org/10.1016/j.curobgyn.2003.10.010

[40] Hasan, R., Baird, D.D., Herring, A.H., Olshan, A.F., Jonsson Funk, M.L. and Hartmann, K.E. (2009) Association between First-Trimester Vaginal Bleeding and Miscarriage. Obstetrics \& Gynecology, 114, 860-867. http://dx.doi.org/10.1097/AOG.0b013e3181b79796 
[41] de Waard, M.W., Ankum, W.M., Bonsel, G.J., Vos, J., Biewenga, P. and Bindels, P.J.E. (2003) The Natural Course of Spontaneous Miscarriage: Analysis of Signs and Symptoms in 188 Expectantly Managed Women. British Journal of General Practice, 53, 704-708.

[42] Poulose, T., Richardson, R., Ewings, P. and Fox, R. (2006) Probability of Early Pregnancy Loss in Women with Vaginal Bleeding and Singleton Live Fetus at Ultrasound Scan. Journal of Obstetrics \& Gynaecology, 26, 782-784. http://dx.doi.org/10.1080/01443610600984412

[43] Murphy, F. and Philpin, S. (2010) Early Miscarriage as "Matter out of Place”: An Ethnographic Study of Nursing Practice in a Hospital Gynaecological Unit. International Journal of Nursing Studies, 47, 534-541. http://dx.doi.org/10.1016/j.ijnurstu.2009.10.011

[44] Nielsen, S., Hahlin, M. and Platz-Christensen, J. (1999) Randomised Trial Comparing Expectant with Medical Management for First Trimester Miscarriages. British Journal of Obstetrics and Gynaecology, 106, 804-807. http://dx.doi.org/10.1111/j.1471-0528.1999.tb08401.x

[45] Nielsen, S. and Hahlin, M. (1995) Expectant Management of First-Trimester Spontaneous Abortion. The Lancet, 14, 84-86. http://dx.doi.org/10.1016/S0140-6736(95)90060-8

[46] Shelley, J.M., Healy, D. and Grover, S. (2005) A Randomised Trial of Surgical, Medical and Expectant Management of First Trimester Spontaneous Miscarriage. Australian and New Zealand Journal of Obstetrics and Gynaecology, 45, 122-127. http://dx.doi.org/10.1111/j.1479-828X.2005.00357.x

[47] Marquardt, U. (2011) Management of Miscarriage and Ectopic Pregnancy. Emergency Nurse, 19, 29-35. http://dx.doi.org/10.7748/en2011.11.19.7.29.c8814

[48] Gracia, C.R., Sammel, M.D., Chittams, J., Hummel, A.C., Shaunik, A. and Barnhart, K.T. (2005) Risk Factors for Spontaneous Abortion in Early Symptomatic First-Trimester Pregnancies. Obstetrics \& Gynecology, 106, 993-999.

[49] Cramer, D.W. and Wise, L.A. (2000) The Epidemiology of Recurrent Pregnancy Loss. Seminars in Reproductive Medicine, 18, 331-339. http://dx.doi.org/10.1055/s-2000-13722

[50] Yang, C.J., Stone, P. and Stewart, A.W. (2006) The Epidemiology of Recurrent Miscarriage: A Descriptive Study of 1214 Prepregnant Women with Recurrent Miscarriage. Australian and New Zealand Journal of Obstetrics and Gynaecology, 46, 316-322. http://dx.doi.org/10.1111/j.1479-828X.2006.00599.x

[51] Maconochie, N., Doyle, P., Prior, S. and Simmons, R. (2007) Risk Factors for First Trimester Miscarriage-Results from a UK-Population-Based Case-Control Study. BJOG: An International Journal of Obstetrics and Gynaecology, 114, 170-186. http://dx.doi.org/10.1111/j.1471-0528.2006.01193.x

[52] Dart, R.G., Kaplan, B. and Varaklis, K. (1999) Predictive Value of History and Physical Examination in Patients with Suspected Ectopic Pregnancy. Annals of Emergency Medicine, 33, 283-290. http://dx.doi.org/10.1016/S0196-0644(99)70364-1

[53] James, J.W. and Friedman, R. (2006) Sorgbearbetning: Ett handlingsprogram för känslomässig läkning vid dödsfall, separationer och andra förluster. Svenska institutet för sorgbearbetning, Värnamo.

[54] Ancker, T., Gebhardt, A., Andreassen, S. and Botond, A. (2012) Tidig förlust: Kvinnors upplevelse av missfall. Nordic Journal of Nursing Research, 32, 32-36. http://dx.doi.org/10.1177/010740831203200107

[55] Harvey, J., Moyle, W. and Creedy, D. (2001) Women’s Experience of Early Miscarriage: A Phenomenological Study. Australian Journal of Advanced Nursing, 19, 8-14.

[56] Simmons, R.K., Singh, G., Maconochie, N., Doyle, P. and Green, J. (2006) Experience of Miscarriage in the UK: Qualitative Findings from the National Women’s Health Study. Social Science \& Medicine, 63, 1934-1946. http://dx.doi.org/10.1016/j.socscimed.2006.04.024

[57] Swanson, K.M. (1999) Research-Based Practice with Women Who Have Had Miscarriages. Image: The Journal of Nursing Scholarship, 31, 339-345. http://dx.doi.org/10.1111/j.1547-5069.1999.tb00514.x

[58] Corbet-Owen, C. (2003) Women's Perceptions of Partner Support in the Context of Pregnancy Loss(es). South African Journal of Psychology, 33, 19-27. http://dx.doi.org/10.1177/008124630303300103

[59] Andersson, I.-M., Nilsson, S. and Adolfsson, A. (2012) How Women Who Have Experienced One or More Miscarriages Manage Their Feelings and Emotions When They Become Pregnant again-A Qualitative Interview Study. Scandinavian Journal of Caring Sciences, 26, 262-270.

[60] Bunge, M., Mühlhauser, I. and Steckelberg, A. (2010) What Constitutes Evidence-Based Patient Information? Overview of Discussed Criteria. Patient Education and Counseling, 78, 316-328. http://dx.doi.org/10.1016/j.pec.2009.10.029

[61] Nilsen, E.S., Myrhaug, H.T., Johansen, M., Oliver, S. and Oxman, A.D. (2006) Methods of Consumer Involvement in Developing Healthcare Policy and Research, Clinical Practice Guidelines and Patient Information Material. Cochrane Database of Systematic Reviews, 3, Article ID: CD004563. 
[62] Muhlhauser, I. and Berger, M. (2000) Evidence-Based Patient Information in Diabetes. Diabetic Medicine, 17, 823829. http://dx.doi.org/10.1046/j.1464-5491.2000.00383.x

[63] Bunge, M., Mühlhauser, I. and Steckelberg, A. (2010) What Constitutes Evidence-Based Patient Information? Overview of Discussed Criteria. Patient Education and Counseling, 78, 316-328.

[64] Garner, M., Ning, Z. and Francis, J. (2012) A Framework for the Evaluation of Patient Information Leaflets. Health Expectations: An International Journal of Public Participation in Health Care and Health Policy, 15, 283-294.

[65] Nilsen, E., Myrhaug, H., Johansen, M., Oliver, S. and Oxman, A.D. (2006) Methods of Consumer Involvement in Developing Healthcare Policy and Research, Clinical Practice Guidelines and Patient Information Material. Cochrane Database of Systematic Reviews, 3, Article ID: CD004563.

[66] Robins, D., Holmes, J. and Stansbury, M. (2010) Consumer Health Information on the Web: The Relationship of Visual Design and Perceptions of Credibility. Journal of the American Society for Information Science and Technology, 61, 13-29. http://dx.doi.org/10.1002/asi.21224 


\section{Appendix: Facts Text to Couples}

\section{Miscarriage \\ 2. Symptoms}

3. Classification of miscarriage

1) Full miscarriage

2) Incomplete miscarriage

3) Delayed miscarriage (missed abortion)

4) Threatened miscarriage

5) Repeated miscarriages

\section{Treatment of miscarriage}
1) Full miscarriage
2) Incomplete miscarriage and delayed miscarriage
3) Cautious treatment
4) Medical Treatment

5. Causes of Miscarriage

6. Differential diagnosis of miscarriage

7. Ectopic pregnancy

8. Experience of miscarriages
1) Sadness at miscarriage
2) Typical reactions to grief with miscarriage

\section{The woman's experience of the miscarriage}

10. The partner's experience of the miscarriage

11. Faced with a new pregnancy

\section{Miscarriage}

Miscarriage is defined as a spontaneous pregnancy termination that occurs before gestational week twentytwo. Approximately one in every five known pregnancies ends with a miscarriage. A known pregnancy is characterized by positive pregnancy test. A percentage of pregnancies terminate before the woman even knows that she was pregnant. The miscarriage can then show up as a late menstruation with more bleeding than usual. Typically a miscarriage begins with bleeding and abdominal pain. Bleeding during a pregnancy is an immediate cause for concern for the woman which can give her the anxiety that her pregnancy can end in miscarriage. The causes of bleeding during a pregnancy may be a miscarriage, ectopic pregnancy, molar pregnancy or other cause. Miscarriage is characterized by bleeding and is not always diagnosed.

\section{Symptoms}

The most common symptoms of miscarriage are bleeding and pain. The bleeding can vary in amount and in type. It can continue for a few days and stop after a time. The pain can range from a dull ache in the lower abdomen to more acute cramp type pain. The dull pain can be compared to menstrual pain and the pain can also be localized in the lower back.

\section{Classification of miscarriage}

Miscarriage divided into early and late miscarriage. Early miscarriage occurs before the gestational week thirteen and late miscarriage is designated beyond the thirteen week mark. Miscarriages are diagnosed using an ultrasound examination and are classified as: complete, incomplete, delayed miscarriage (missed abortion) and threatened miscarriage. Several miscarriages in a row is called recurrent miscarriage.

1) Full miscarriage

Full miscarriage defines that the entire pregnancy has spontaneously been aborted. All fetal, placental and membranes have been expelled at the same time. The associated bleeding gradually decreases and disappears, normally within a week. The uterus contract when the pregnancy is terminated with fetal matter evacuated and is reduced in size. A vaginal ultrasound evidences an empty uterine cavity and closed cervix.

2) Incomplete miscarriage

An incomplete miscarriage usually occurs after the tenth week with the pregnancy being expelled from the uterus in stages. The symptoms of incomplete miscarriage are lower abdominal pain and heavy bleeding. The diagnosis is made by an ultrasound examination. The bleeding may continue until all of the pregnancy (fetus, 
membranes and placenta has been expelled). Incomplete miscarriage will normally require some form of treatment because it is vitally important to ensure that all of the pregnancy has been removed to prevent complications.

3) Delayed miscarriage (missed abortion)

Delayed miscarriage (missed abortion) means that the fetus has died in the womb without any bleeding occurring. The woman may experience a brief period episode of vaginal spotting or evidence a brownish discharge that rapidly disappears. The diagnosis is normally made by the ultrasound examination. Women may seek medical attention because of the dark discharge or because her pregnancy symptoms such as nausea, fatigue and breast pain have disappeared.

The ultrasound reveals an empty embryonic sac without a living fetus. The reason that the uterus can retain a dead fetus is because the placenta continues to produce progesterone and estrogen. That some of the dead fetus tissue is retained in the uterus is because the placenta's production of progesterone is intact for a longer time or a shorter time while a decrease in estrogen occurs. The estrogen production can only be maintained as long as there is a live fetus. This changing hormone production leads to uterus muscle volatility and the ability to contract is reduced which prevents the ejection of the pregnancy matter.

The treatment of miscarriage depends upon the age of the pregnancy, bleeding and signs of infection. With a pregnancy of less than thirteen weeks an expectance may be an option.

4) Threatened miscarriage

Threatened abortion occurs in approximately one of seven pregnancies and of these around 20 percent of these results in a miscarriage. Symptoms of an imminent miscarriage are minor vaginal bleeding in the first trimester in combination with pain, particularly in the lower back. The bleeding is typically minor and disappears quickly. When the threatened abortion runs its course, the pregnancy proceeds and the woman gives birth to a child around the expected date of delivery. To determine if the miscarriage is threatening or complete a vaginal ultrasound is performed. When the diagnosis is threatened miscarriage the vaginal ultrasound reveals an intact cervix with the cervical canal closed which confirms a viable pregnancy with a uterine size consistent with the estimated gestational age.

5) Repeated miscarriages

Repeated Miscarriage affects one percent of all couples trying to have children. Repeated miscarriage is defined as three or more successive miscarriages that occur approximately at the same time in the pregnancy. After experiencing a miscarriage the risk for a subsequent miscarriage during the next pregnancy is still the same as normal, in the ten to twenty percent range. After the couple has had a third miscarriage the risk of the next pregnancy terminating in miscarriage is fifty percent if no investigation is done. The reason that the couple is experiencing repetitive miscarriages may be due to maternal, sperm or genetic issues. A thorough investigation is done after three miscarriages. Depending upon the results of the investigation there may be some treatment that may be prescribed to influence a positive outcome of the next pregnancy.

\section{Treatment of miscarriage}

The treatment of miscarriage depends upon whether the miscarriage is a complete, incomplete or a delayed miscarriage.

1) Full miscarriage

Typically no treatment is necessary for a complete miscarriage because there are still some remnants from the pregnancy in the uterus. In order to ensure that the woman has bled out the entire pregnancy a vaginal ultrasound is performed. A few weeks after the miscarriage occurred a pregnancy test is performed to verify that the miscarriage was complete.

2) Incomplete miscarriage and delayed miscarriage

The diagnosis is made by an ultrasound examination. With the ultrasound, the mouth of the uterus is seen as opened with pregnancy tissue residue present in the opening. A fetus without cardiac activity is present. The residual tissues should be removed to reduce the pain and bleeding and to prevent the risk also of cervical vasogagal shock. The bleeding will continue until the entire pregnancy is aborted.

3) Cautious treatment

If the pregnancy is shorter than twelve weeks and the woman is not bothered by the bleeding, she can elect to wait on the body to heal itself in a natural way to repel pregnancy. In the coming days she will experience vaginal bleeding accompanied with possible acute abdominal pain. The pain might be remedied with paracetamol 
and/or codeine. To eliminate the risk of infection the woman is advised not to bathe or engage in intercourse for the next two weeks. If the body is not capable of completing the miscarriage on its own the woman may need medical treatment.

4) Medical Treatment

Medical treatment means that the woman should be administered a medicine containing prostaglandin to assist the uterus to contract and expel the remains of the pregnancy. Women receiving medical treatment for miscarriage should follow up with hCG in serum or urine tests to rule out ectopic pregnancy and chorionic malignancy. Within fourteen days the woman is called in for an appointment to verify that the pregnancy has totally expelled itself. Should the women experience heavy bleeding, become circulatory influenced or have an infection of the pregnancy tissue she may require a hemostatic curettage.

5) Surgical Treatment

Hemostatic curettage is usually performed with general anesthesia after the cervix is dilated with the administration of prostaglandin. When the hemostatic curettage is scraped the pregnancy tissue is vacuumed out with a suction device. Women who have the hemostatic curettage generally experience several fewer days of bleeding and have less pain than those that elect for expectance or medical treatment. To prevent the risk of infection the woman is advised not to bathe or have sexual intercourse during the next two weeks.

\section{Causes of Miscarriage}

The cause of each individual miscarriage case is seldom known. The most common cause is said to be chromosomal abnormalities. Defects to the fertilized egg, chronic diseases of the woman, diabetes related issues and infections are other common causes of miscarriage. Most of these causes are certainly beyond the influence of the woman. Malformations of the uterus add to risk of miscarriage. The risk of miscarriage increases with the age of the woman. Environmental factors can have the effect of increasing the risk of a miscarriage. If the woman smokes the risk of miscarriage increases with the amount of cigarettes she smokes. It is not surprising that drinking alcohol increases the risk of miscarriage. Women who are happy, relaxed and in control during the first twelve weeks of the pregnancy are at a reduced risk and the opposite might also be said to be true. Women who have experienced stressful and traumatic events during their pregnancy are at an increased risk for miscarriage.

\section{Differential diagnosis of miscarriage}

1) Molar pregnancy (hydatidiform mole)

A molar pregnancy is a rare complication of pregnancy which can mimic the same symptoms as miscarriage such as bleeding and pain. A molar pregnancy is caused by a faulty development of the egg.

The uterus fills with fluid-filled blisters instead of the fetus and placenta. The woman receives a positive pregnancy test because the "grape spirit" produces the same hormone hCG (human chorionic gonadotropin) as a normal placenta. The woman is also not menstruating so she assumes that she is pregnant.

The diagnosis for molar pregnancy is usually made from the combination of the woman's medical history with ultrasound and blood tests. The ultrasound examination shows that the uterus has no viable fetus and is instead filled with blisters. A hemostatic curettage is performed and the contents are suctioned out of the uterus and sent to the pathologist for analysis.

After this procedure has been completed the serum levels of hCG are examined to assure that no molar residual is left. Pregnancy should be abstained from for up to a year until normal hCG levels are attained. The risk of the subsequent pregnancy developing into a molar pregnancy is one in 74 pregnancies.

\section{Ectopic pregnancy}

An ectopic pregnancy occurs when the fertilized egg is implanted outside of the uterine cavity. This is a condition that occurs in roughly two percent of early pregnancies. In ninety-nine percent of all ectopic pregnancies the implantation of the fertilized egg occurs in the fallopian tubes but it can occur in the ovaries and in the abdominal cavity as well.

The symptoms of ectopic pregnancy first appear about six to eight weeks after the last menstrual cycle. The most common symptoms are pain to one side in the lower abdomen and heavy bleeding is never a symptom. Risk factors for ectopic pregnancy are inflammation of the ovaries, intrauterine devices (IUD), sterilization, former fallopian tube surgeries, previous ectopic pregnancy or infertility.

The diagnosis is based on the woman's health history, ultrasound and blood tests on serum levels of hCG. The 
ultrasound examination reveals no fetus in the uterus. Treatment can be either medical or surgical, depending on the woman's symptoms.

\section{Experience of miscarriages}

1) Sadness at miscarriage

The woman and her partner often receive the news and the finding that the pregnancy is no longer viable. When this is confirmed by the ultrasound screen that does not show any evidence of life they can lapse into a state of shock and feel a deep sense of despair. In this type of unbalanced emotional state they are often unable to fully comprehend the information that they are being given and they end up going home full of their concerns. It is vitally important that the grieving couple's sad state is recognized and that they are treated professionally with adequate empathy and sympathy. The grief produced by a miscarriage is extremely difficult and very trying emotionally which can make it difficult to manage. The loss of the dream comes swiftly and unexpectantly without any warning signs save for the preliminary symptoms. Grief that is not processed can develop into a guilt against the next pregnancy. Couples react differently to grief. They may experience dizziness, anxiety or the inability to sleep. After a loss such as miscarriage it is normal and natural to feel substantial grief. In today's society we are socialized to believe that these feeling may be unnatural and abnormal.

2) Typical reactions to grief with miscarriage:

Reduced concentration... A person in mourning typically has difficulty concentrating and they are often fully occupied with the feelings that the grief has brought to them.

A sense of anesthesia... In a sense it is sort of anesthesia. The feeling can be numbing both physically and emotionally. The anesthesia lasts for different lengths of time depending on the individual.

Irregular sleep... Sleeping disruptions or irregularities may vary from day to day. They can switch between not being able to sleep to sleeping unusually deep and long.

Change in eating habits... Similarly to the sleeping disorders, eating problems may vary from not having any appetite at all to eating too much. These reactions too can vary from day to day.

Emotional roller-coaster... The emotions provoked by such a disappointing event leaves the victim feeling emotionally and physically exhausted because of the emotional swings

\section{The woman's experience of the miscarriage}

Having a spontaneous abortion means the loss of an expected child to the woman regardless at what stage of her pregnancy this has occurred. The miscarriage itself symbolizes the loss of a baby, maternity, hopes and dreams for the future that women feel ownership of from the moment of conception to the reinforcement of the positive pregnancy test. Women describe feeling of sadness, pain anxiety, guilt and profound emptiness. They also feel some fear and panic surrounding the whole experience as they try to understand what exactly has happened to them. Miscarriage is the last thing in the world that a mother to be would wish to happen and an unexpected shock of this magnitude leads the women to question themselves as to why it happened to them.

Many women describe having feelings that something was wrong with their pregnancy before the miscarriage occurred. Women naturally want to find explanations for why the miscarriage happened and they can end up blaming themselves for the outcome. They can see their bodies as incapable of carrying out the pregnancy and giving birth to a child or they can blame themselves for not doing everything they could to prevent the miscarriage. The women who have reoccurring miscarriages experience it as a personal failure so it is vitally important that the healthcare provided to them will free them from the guilt and the anxiety that is a result of the episode. It is important that they can feel that there was not anything that they did wrong. The loss of the pregnancy can lead to an internal conflict in the woman and this conflict can easily lead to depression if her feelings are left unresolved. If the woman does not share the disappointment it can lead to a feeling of isolation and further anxiety. It can also lead to anxiety and suffering when it comes to a new pregnancy. The loss of the pregnancy is an emotional, physical and mental strain for women when their immediate plans for the future are unexpectantly dashed. Partly as a consequence of this the women may feel that they have been provided with inadequate information about miscarriage when it occurs. There are women that have had bleeding during their pregnancy that called the healthcare for advice and were told that the bleeding was not dangerous and they are not to worry. This may cause them to feel rejected. Women who end up going to the emergency ward with bleeding feel left out because they may have to wait an inordinate amount of time for a doctor to tell them what they believe. Women who suffer a miscarriage experience it as a personal failure. They often end up attributing the blame for the failure on themselves. 


\section{The partner's experience of the miscarriage}

The partner of the woman has a different experience of the miscarriage than the woman does. They might find the event to be frightening. It is difficult to stand idly by and watch the woman writhing in pain and bleeding. The partner is worried and afraid of something happening to the woman. The partner may cry at first as their initial reaction when they receive the news that there has been a miscarriage and then they want to move on. It is difficult for them to understand why the woman must continue to mourn for days and even weeks while having the need to think and talk about what happened to them. If the partner does not feel like talking about the miscarriage when the woman does it can be a source of conflict and have a distancing effect on the relationship. The partner does not have the same needs as the woman to talk about the miscarriage. This is actually quite normal and understandable as the partner does not perceive the disappointment on the level as the woman who afterall had a developing fetus in her own body. With the loss, the partner tries to show strength and protectiveness. They put their own feelings of grief and anger aside. It may be difficult for the partner to provide emotional support when they are experiencing their own feelings of being stressed and at a loss of explanation for the event. The partner's intention is to provide emotional support which they may attempt to do by practical awareness rather than emotionally. The woman might find this type of support inadequate which in turn may lead the partner to feel guilty and unappreciated.

\section{Faced with a new pregnancy}

The initial time after the miscarriage is understandably difficult and the tears can come out of nowhere without any sense of control. Women can have the feeling that they will never come to feel good again. Some of this can be attributed to the presence of high hormones in the body. Many couples are still longing for a child after the miscarriage but it is quite common for them to wonder if they dare to try it again. It is recommended that the woman think things through thoroughly and wait to attempt to get pregnant again until she has resolved her feelings about her miscarriage. This will give the couple a fresh opportunity to make the necessary decisions as to when they will be ready for a new pregnancy. During these difficult times it is important that they do not avoid being close to one another and avoid intimacy. But it is good to wait on a new pregnancy until the menstrual cycle has returned to normal.

Women who have suffered a miscarriage often have mixed feelings initially about getting pregnant again. With the advent of a new pregnancy their feelings my oscillate between feeling of joy to feelings of fear and anxiety. It is common for the woman to distance herself from a new pregnancy. She understandably wants to protect herself from the strong sense of disappointment that she experienced when she miscarried. Even if the woman manages to get pregnant again she may find it difficult to the feel real joy attached to it. To make the potential disappointment of another miscarriage more manageable the couple may avoid making the purchase of baby things, they may tell their friends and family that they are expecting another child or that they have an appointment for enrollment for women's healthcare. It is not uncommon for women to focus and pay close attention to their pregnancy symptoms. Knowing that the symptoms have a calming effect on the woman. Symptoms such as nausea, fatigue and sore breasts give her that sense of security and the sense of identity of a pregnant woman. The absence of bleeding also brings her comfort. Many women feel more secure once they have had an early ultrasound examination to confirm that they have a live fetus in their womb. It is a matter left to the individual how long this makes the woman feel secure. They know from their previous experience with miscarriage that there are no guarantees.

Many of these women need extra support and advice when they enter a new pregnancy. When they get a positive pregnancy test result it may create an anxiety that makes it difficult to manage by herself. She may find that she needs professional counseling with a counselor or a midwife where she can talk about her miscarriage experience and her concerns for the new pregnancy. Waiting for the call to enroll in the women's healthcare seems like a long time for the woman who is managing her fear and anxiety on her own. There are also women that go into the new pregnancy without being worried about another miscarriage and who dare to believe that they are going to be successful. 